\title{
Role of aliskiren in blood pressure control and renoprotection
}

\author{
This article was published in the following Dove Press journal: \\ International Journal of Nephrology and Renovascular Disease \\ 2I March 20II \\ Number of times this article has been viewed
}

\author{
Hernán Trimarchi \\ Department of Medicine, Division \\ of Nephrology, Hospital Británico \\ de Buenos Aires, Buenos Aires, \\ Argentina
}

Correspondence: Hernán Trimarchi Hospital Británico de Buenos Aires, Perdriel 74 (1280) Buenos Aires, Argentina

Tel +54 II 43096400

Fax +54 II 43043393

Email htrimarchi@hotmail.com

\begin{abstract}
Patients with chronic renal disease are at increased risk for the development of cardiovascular disease, which is the main cause of death in this growing population. Among the risk factors involved, hypertension and proteinuria are major contributors to kidney damage and, if not controlled, may eventually lead to the progression of renal failure and end-stage renal disease. Both proteinuria and hypertension can be primary pathologic events or can appear as complications of other disease processes. Initially, these two factors may operate separately but, as progression ensues, both processes generally combine, potentiating their effects and hastening renal damage. Therefore, strategies to reduce blood pressure and proteinuria are essential in order to slow the worsening of many nephropathies. Therapies that target the renin-angiotensin system offer particular benefit, as hypertension and proteinuria can be precisely reduced with angiotensin-converting enzyme inhibitors and/or angiotensin receptor blockers. However, with this intervention, plasma renin activity remains high, and although primary endpoints may be controlled, elevated renin concentration can contribute to cardiovascular damage. Aliskiren, a direct renin inhibitor, is the first example of a novel class of antihypertensive drugs with potent antiproteinuric effects, which, alone or combined, can contribute to delaying the progression of kidney disease.
\end{abstract}

Keywords: aliskiren, proteinuria, hypertension, chronic kidney disease, renoprotection

\section{Introduction to blood pressure management and renoprotection}

Hypertension and diabetes mellitus account for over $50 \%$ of cases of chronic kidney disease. High blood pressure itself is a major risk factor for the progression of renal disease, affecting approximately $30 \%$ of the adult population in Western countries. ${ }^{1}$ As pointed out by Ritz ${ }^{2}$ in an editorial regarding the 2007 World Kidney Day, "High blood pressure, not necessarily the 'disease' hypertension according to current definitions (JNC7), is a major killer ..." If a subject presents a blood pressure of $140 \mathrm{~mm}$ $\mathrm{Hg}$ systolic, the risk of stroke or myocardial infarction is double that of someone with a blood pressure of $120 \mathrm{~mm} \mathrm{Hg}$ systolic. However, with a systolic blood pressure of 120-130 mm Hg, rather than $120 \mathrm{~mm} \mathrm{Hg}$ or lower, the risk of end-stage renal disease is approximately $62 \%$ and rises to nearly $160 \%$ with a pressure of $130-140 \mathrm{~mm} \mathrm{Hg} .{ }^{3}$ Therefore, an aggressive approach to blood pressure reduction is mandatory. However, it is estimated that only a small percentage of hypertensive patients have adequate blood pressure control. This situation can, in part, explain the growing number of cases of chronic renal failure. According to the recently published United States Renal Data System (USRDS) report, in the general population, $31 \%$ of hypertensives are unaware 
of their diagnosis, $11 \%$ are aware but not treated, $24 \%$ are treated but uncontrolled, and only $34 \%$ of subjects are aware, treated, and well controlled. Surprisingly, in patients with chronic kidney failure stages 3-4 (glomerular filtration rate $15-60 \mathrm{~mL} / \mathrm{min}$ ), 24\% are unaware of being hypertensive, $6 \%$ are aware but not treated, 50\% are aware but poorly controlled, and only $20 \%$ have their blood pressure controlled $(<130-180 \mathrm{~mm} \mathrm{Hg}) .{ }^{4}$ In the same report, it is shown that $91.4 \%$ of chronic kidney patients are hypertensive. ${ }^{5}$ This grim reality may partially explain why the adjusted rate of prevalent cases of end-stage renal disease in the US rose $1.9 \%$ in 2008 (the same rate growth as that seen in 2007) to 1699 per million population. This rate is nearly $20 \%$ higher than that seen in 2000. The annual rate of increase has remained stable between $1.9 \%$ and $2.3 \%$ since $2003 .{ }^{6}$

Proteinuria is another relevant target, as it is a major risk factor for renal disease progression. ${ }^{7-9}$ Proteinuria can be due to primary glomerulopathies (focal and segmental glomerulonephritis, membranous nephropathy, minimal change disease, Berger's disease, membranoproliferative glomerulonephritis), which are the third most likely cause of end-stage renal disease in the adult population and an important cause of secondary hypertension, or to secondary glomerular damage as a result of primary hypertension, diabetes mellitus, reflux nephropathy, or other causes of renal disease. A coexistent diagnosis of hypertension and diabetes increases the risk of adverse cardiovascular and renal outcomes. This increased risk extends to a diastolic blood pressure of $\geq 83 \mathrm{~mm} \mathrm{Hg}$ and a systolic blood pressure of $\geq 127 \mathrm{~mm} \mathrm{Hg} .{ }^{10,11}$ Reduction of proteinuria by $>30 \%$ within the first 6-12 months of treatment in patients with chronic kidney disease has been shown to predict long-term renal and cardiovascular outcomes. ${ }^{8,12}$ Moreover, the management of albuminuria in normotensive or hypertensive patients with diabetes may slow progression of diabetic nephropathy. ${ }^{13}$ Microalbuminuria itself, an early marker of kidney vascular dysfunction, is a strong prognostic indicator of mortality and cardiovascular disease in hypertension and diabetes mellitus. ${ }^{14,15}$ Therefore, one of the main goals to slow the progression of renal disease is an adequate and not unusually aggressive control of blood pressure and the reduction of proteinuria to its lowest possible level.

In this regard, the pharmacological manipulation of the renin-angiotensin-aldosterone system (RAAS) is an important tool to employ, as renin, angiotensin II, and aldosterone are important molecules with hemodynamic and inflammatory effects both systemically and locally, particularly in the kidney. Angiotensin-converting enzyme inhibitors (ACEIs) and angiotensin receptor blockers (ARBs) reduce proteinuria and blood pressure, either alone or combined. ${ }^{16}$ However, by attenuating feedback inhibition of renin release, ACEIs and ARBs effects lead to an increase in plasma renin concentration and activity, rendering incomplete inhibition of the RAAS system. ${ }^{17,18}$ Moreover, inhibition of ACE causes an increase in angiotensin I, which is then available for conversion to angiotensin II by ACE-independent pathways not blocked by ACEIs, namely cathepsins and tonins. ${ }^{19-21}$ Consequently, despite adequate blood pressure control, angiotensin II levels increase aldosterone levels to certain degrees, rendering these inflammatory molecules free to play an active role in tissue remodeling and scarring. Henceforth, it is tempting and reasonable to assess the effects of a different pharmacologic strategy that blocks the RAAS upstream completely. Aliskiren is the first known representative of a new class of nonpeptide orally active renin inhibitors that block the RAAS at its rate-limiting step and induce a net reduction in plasma renin activity and angiotensin II and aldosterone levels. ${ }^{22-24}$ Aliskiren has been assessed in recent years as an efficient antihypertensive drug, either alone or in combination with other drugs. Its antiproteinuric effects are notorious and may be independent of its antihypertensive effects, showing that aliskiren alone or combined can further decrease proteinuria and the risk of renal disease progression. ${ }^{25}$ This suggests that renin- or angiotensin-independent pathways may be involved in inflammatory processes of which proteinuria is a disease activity marker and that aliskiren can abrogate.

\section{Review of aliskiren pharmacology, mode of action, pharmacokinetics, and effects on renal hemodynamics}

The direct renin inhibitor aliskiren is an octanamide and a nonpeptide piperidine with high affinity and specificity for human renin, ${ }^{25}$ and it inhibits the enzyme renin by binding to its catalytic site, thus blocking the RAAS at its point of activation. ${ }^{26}$ In this respect, angiotensin I, angiotensin II, and aldosterone levels decrease, and their hemodynamic and inflammatory effects are abolished. Therefore, aliskiren impedes efferent arteriolar vasoconstriction and diminishes the glomerular filtration fraction, salt and water absorption, and angiotensin II-induced inflammatory actions. Moreover, it blocks renin and prorenin activity while renin and prorenin levels remain high. ${ }^{22,24,25}$

A recently discovered (pro)renin receptor activates when exposed to either renin or prorenin, the inactive form of renin. ${ }^{27}$ The (pro)renin receptor, in turn, enhances renin catalytic activity and allows prorenin to display catalytic activity without its proteolytic conversion to renin. This (pro) 
renin receptor-induced prorenin activation could explain how prorenin exerts pathological effects in diabetic patients, where prorenin represents approximately $95 \%$ of total circulating renin. ${ }^{28}$ Interestingly, recent data have shown that renin and prorenin induce activation of the extracellular signal-regulated kinase (ERK) pathway, independent of angiotensin II. In this respect, aliskiren has no (pro)renin receptor-blocking action. Therefore, ACEIs, ARBs, and aliskiren all increase renin concentration, which could conceivably induce (pro)renin receptor signaling without the involvement of angiotensin II, suggesting that blockade of the (pro)renin receptor might be an alternative or an adjunct to renin-angiotensin system inhibition, particularly in conditions with high renin and/or prorenin levels. ${ }^{28}$ High prorenin levels are closely associated with the severity of diabetic complications. In this respect, in diabetics, increased prorenin levels have been shown to be associated with microalbuminuria and with the development of nephropathy. ${ }^{29,30}$ However, aliskiren still blocks the tissue renin-angiotensin system, because at the (pro)renin receptor level, activated prorenin can immediately be blocked by aliskiren. The result would be angiotensin II production not occurring. ${ }^{28}$ Interestingly, renin bound to the (pro)renin receptor presents much more enhanced catalytic activity than soluble renin. ${ }^{31}$ The cloning of a functional receptor for both renin and prorenin suggests that renin and prorenin may exert direct angiotensin II-independent tissue-damaging effects by increasing the expression of profibrotic pathways and molecules, such as transforming growth factor- $\beta .^{32}$ Additionally, the receptor may amplify renin-induced angiotensin II-dependent effects. Plasma renin activity is blocked only by aliskiren. Elevated baseline plasma renin activity in untreated patients has been associated with end-organ damage, such as left ventricular hypertrophy and renal dysfunction, ${ }^{33,34}$ probably due to high angiotensin II levels. Renin inhibition with aliskiren therefore offers the chance of enhanced RAAS suppression and improved end-organ protection either alone or in combination with other antihypertensive drugs. ${ }^{35}$

Aliskiren is poorly absorbed, with an absolute oral bioavailability of $2.5 \%$ with maximum plasma aliskiren concentrations reached within 1-3 hours of oral administration. ${ }^{36,37-39}$ Although food has a big effect on the pharmacokinetics of aliskiren, the resulting decreases in aliskiren exposure are not considered clinically relevant. ${ }^{40}$ Steady-state plasma concentrations are reached 5-8 days after once-daily oral administration of aliskiren. ${ }^{36,41}$ The half-life of oral aliskiren is around 24 hours; ${ }^{40}$ it is approximately $50 \%$ protein bound in human plasma, and protein binding is independent of aliskiren plasma concentration. ${ }^{41}$ Hepatic and renal metabolism are not major routes of aliskiren elimination. ${ }^{40,41}$ Following a single oral $300 \mathrm{mg}$ dose, aliskiren has an elimination halflife of 40 hours in healthy volunteers. ${ }^{42}$ Excretion is almost completely by the fecal route $(91.5 \%)$, with $77.5 \%$ of the dose excreted as unchanged drug. ${ }^{43}$ The pharmacokinetics of aliskiren are not affected by sex, ${ }^{36,41}$ body mass index, ${ }^{36,41}$ or race and are similar in Chinese, Japanese, and Caucasian ${ }^{4-46}$ patients. The pharmacokinetics of aliskiren in patients with hepatic impairment, mild to severe renal disease, ${ }^{36,41}$ or type 2 diabetes ${ }^{42}$ are no different from those of healthy volunteers. Thus, initial dosage adjustments are not necessary in patients with renal or hepatic impairment. ${ }^{36,41}$

Aliskiren has a low potential for clinically relevant interactions with other drugs. ${ }^{40,41}$ However, coadministration of aliskiren with irbesartan decreased the aliskiren maximum concentration by $50 \%$ after multiple dosing. ${ }^{36,41}$ The exposure to aliskiren was not altered by coadministration of furosemide. ${ }^{47}$ However, furosemide decreased by $28 \%$ and $49 \%$ with concomitant aliskiren administration. Although the clinical significance of this is unclear, the effects of furosemide should be monitored. ${ }^{41}$ When aliskiren was coadministered with rifampicin, the latter reduced aliskiren concentration by $39 \% .{ }^{48}$ Coadministration of aliskiren with potent P-glycoprotein inhibitors (cyclosporine, quinidine, and verapamil) is virtually contraindicated because aliskiren plasma concentrations significantly increase, and aliskiren and moderate P-glycoprotein inhibitors (ketoconazole, itraconazole, clarithromycin, telithromycin, erythromycin, and amiodarone) should be coadministered with caution. Grapefruit juice should not be taken together with aliskiren. ${ }^{41}$

One concern is the potential adverse effect of high circulating renin concentrations after aliskiren therapy. As mentioned previously, aliskiren binds to the active site of renin, reducing its activity (plasma renin activity) and angiotensin II production. Diminished angiotensin II levels stimulate renin secretion (plasma renin concentration). The potential negative consequence of high renin concentration is that renin may bind to a renin receptor and trigger yet unknown events. ${ }^{49}$ However, an important contributor to the exaggerated renin response is interference by the renin inhibitor in the renin assay causing overestimation of the renin concentration. ${ }^{50}$ Thus, this renin response may not actually represent an increase in enzymatically active renin molecules in plasma. The question of whether this increase in renin concentration has any effect remains unanswered. Although aliskiren lowers plasma renin activity, renin concentration rises, and ACEIs and ARBs increase both. ${ }^{51,52}$ As mentioned previously, high levels of renin can activate the prorenin/renin receptor, 
which aside from activating prorenin, can possibly initiate ERK1/2 signaling and transform growth factor- $\beta$ activation and other potentially serious complications. ${ }^{25,53}$ However, ACEIs and ARBs also leave these issues unresolved with a partial inhibition of angiotensin II concentration, despite good blood pressure control. Some authors have argued against renin inhibition, because plasma renin concentrations attained after aliskiren are higher than those obtained after ARBs. ${ }^{54}$ However, in some studies in mice, ARBs have caused higher plasma renin concentrations than aliskiren. This discrepancy could partly be due to the method employed to measure renin concentrations in mice and humans. ${ }^{55}$

Plasma renin activity is blocked only by aliskiren. Elevated baseline plasma renin activity in untreated patients has been associated with end-organ damage, such as left ventricular hypertrophy and renal dysfunction, ${ }^{56,57}$ probably due to high angiotensin II levels. ${ }^{58}$ Renin inhibition with aliskiren therefore offers the chance of enhanced RAAS suppression and improved end-organ protection, either alone or in combination with other antihypertensive drugs. ${ }^{25,59}$ The kidney is an important site of the uptake of renin inhibitors, and aliskiren has been found in renal glomeruli, renal arteries, and capillaries. ${ }^{60,61}$ Aliskiren may act directly on the renin-secreting juxtaglomerular cell to influence prorenin processing and renin release..$^{50}$

\section{Efficacy studies and organ protection \\ Efficacy studies}

The therapeutic efficacy of aliskiren will be outlined in this section at a dosage of $150 \mathrm{mg} /$ day or $300 \mathrm{mg} /$ day alone and compared with placebo and ACEIs or ARBs and/or combined with hydrochlorothiazide, valsartan, valsartan plus hydrochlorothiazide, amlodipine, amlodipine plus hydrochlorothiazide, ramipril, and atenolol. In general, adult patients were enrolled in these trials with diastolic blood pressures $>90-95 \mathrm{~mm} \mathrm{Hg}$ and $<110 \mathrm{~mm} \mathrm{Hg}$ or mean systolic blood pressures between $>160 \mathrm{~mm} \mathrm{Hg}$ and $<200 \mathrm{~mm} \mathrm{Hg}$. Patients with secondary hypertension, severe cardiovascular disease, uncontrolled diabetes mellitus, and hepatic or renal disease were excluded from most studies. A concise, thorough, updated review has recently been published. ${ }^{62}$

\section{Monotherapy}

In the 8-week, placebo-controlled trials, monotherapy with aliskiren $150 \mathrm{mg}$ /day or $300 \mathrm{mg} /$ day reduced baseline systolic and diastolic blood pressure to a significantly greater extent than placebo in patients with stage 1 to stage 2 hypertension. ${ }^{63-67}$ The antihypertensive efficacy of aliskiren monotherapy was also demonstrated in subgroups of patients, including diabetic and obese patients and those with metabolic syndrome. ${ }^{68}$

\section{Comparisons with other agents}

Across a number of trials in patients with hypertension, aliskiren monotherapy was generally as effective as hydrochlorothiazide, ramipril, lisinopril, irbesartan, atenolol, valsartan, and losartan at reducing blood pressure in shortterm studies. In long-lasting, double-blind trials, aliskirenbased therapy was at least as effective as ramipril-based therapy ${ }^{69}$ and more effective than hydrochlorothiazide-based therapy. ${ }^{70}$

Aliskiren $150-300 \mathrm{mg} /$ day was more effective than irbesartan $150-300 \mathrm{mg} / \mathrm{day}^{71}$ and generally as effective as valsartan $160-320 \mathrm{mg} / \mathrm{day}^{72}$ and losartan $100 \mathrm{mg} /$ day $^{73}$ in lowering blood pressure. Aliskiren did not differ significantly from atenolol in lowering systolic blood pressure in a study in which patients received aliskiren $150 \mathrm{mg} /$ day or atenolol $50 \mathrm{mg} /$ day for 6 weeks followed by 6 weeks on double the initial dose of the agents. ${ }^{74}$ However, reductions in diastolic blood pressure were significantly greater with atenolol than with aliskiren at both 6 weeks and 12 weeks.

\section{Combination therapy}

The efficacy ${ }^{75-77}$ of aliskiren in combination with other antihypertensives has been evaluated in randomized, doubleblind or open-label, multicentre trials in which aliskiren $150-300 \mathrm{mg} /$ day was administered in combination with hydrochlorothiazide, valsartan, valsartan plus hydrochlorothiazide, amlodipine, amlodipine plus hydrochlorothiazide, ramipril, and atenolol.

In patients with stage 1 to stage 2 hypertension, combined strategies of aliskiren plus hydrochlorothiazide were more effective than aliskiren, hydrochlorothiazide, or ramipril monotherapies, and at least as effective as amlodipine, in reducing blood pressure in patients with stage 2 hypertension, including patients with diabetes, patients with obesity, patients with metabolic syndrome, African American patients, and aged patients. ${ }^{78-83}$ Patients who received aliskiren plus valsartan had significantly greater blood pressure reductions than with either an individual component or placebo. ${ }^{84}$ The antihypertensive effect of the combination of aliskiren plus valsartan was similar in patients with or without diabetes. ${ }^{36}$ The antihypertensive effects of the aliskiren plus valsartan combination were diminished in African American patients, as was the case with ACEIs, ARBs, and atenolol. ${ }^{36}$ 
Aliskiren in combination with amlodipine was effective in lowering BP in patients with stage 1 to stage 2 hypertension. ${ }^{62}$ First-line therapy with combination aliskiren $150 \mathrm{mg}$ /day or $300 \mathrm{mg}$ /day plus amlodipine $5-10 \mathrm{mg}$ /day provided significantly greater control than the respective monotherapies in patients with stage 2 hypertension. ${ }^{85}$ Combination therapy was also more effective than amlodipine monotherapy as first-line therapy in African-American patients with stage 2 hypertension. ${ }^{86}$ This was also observed irrespective of age, sex, and the presence of diabetes or obesity. ${ }^{62}$ Finally, aliskiren in combination with ramipril led to a significantly greater reduction in blood pressure than with each individual component in hypertensive patients with type 1 or 2 diabetes ${ }^{84}$ In a study combining aliskiren $150 \mathrm{mg} /$ day with atenolol $50 \mathrm{mg} /$ day, there were greater reductions in blood pressure than with aliskiren monotherapy after 12 weeks' treatment. ${ }^{87}$

\section{Safety and tolerability}

Aliskiren was generally well tolerated at doses of 150 or $300 \mathrm{mg} / \mathrm{day}^{62}$ and resulted in an incidence of adverse events similar to placebo. ${ }^{41}$ Adverse events, including uncontrolled hypertension $(2.2 \%),{ }^{36}$ have generally been mild and have infrequently led to discontinuation of therapy. ${ }^{41}$ The most common adverse events reported are headache (5.8\%), nasopharyngitis (2.6\%), and diarrhea (1.4\%). ${ }^{62}$ Aliskiren was also associated with a few cases of cough (1.1\%), although, compared with ACEIs, the rate of cough was approximately one-third to one-half that reported with ramipril or lisinopril. ${ }^{36}$ Although aliskiren has rarely been associated with changes in laboratory parameters, it is still prudent to monitor hemoglobin concentration and serum levels of creatinine, urea, potassium, uric acid, and creatine kinase. ${ }^{36,41,62}$

\section{Organ protection}

In respect of organ protection, although blood pressurelowering effects with aliskiren are well established, its effects on cardiovascular morbidity and mortality are yet to be determined. A clinical program is under way to assess the potential benefits of aliskiren in clinical outcomes. Details on studies on the renoprotective and cardioprotective effects of aliskiren in hypertensive, diabetic subjects with nephropathy (Aliskiren in the Evaluation of Proteinuria in Diabetes [AVOID],${ }^{88}$ reduced left ventricular hypertrophy (Aliskiren in Left Ventricular Hypertrophy [ALLAY]), ${ }^{89}$ symptomatic heart failure (Aliskiren Observation in Heart Failure Treatment [ALOFT] $),{ }^{90}$ acute coronary symptoms, ${ }^{91}$ and postmyocardial infarction with low ejection fraction (Aliskiren Study in Post-MI Patients to Reduce Remodelling [ASPIRE] ${ }^{92}$ are available in the literature.

Aliskiren-based therapy demonstrated positive effects on the markers of cardiovascular and renal damage in hypertensive patients with type 2 diabetes and nephropathy, reducing proteinuria independently of blood pressure control $^{88}$ in patients with reduced left ventricular hypertrophy ${ }^{89}$ or in those with symptomatic heart failure and reduced plasma N-terminal probrain natriuretic peptide. ${ }^{90}$ However, aliskiren therapy did not have a beneficial effect on left ventricular remodeling after myocardial infraction. ${ }^{92}$ Add-on aliskiren $300 \mathrm{mg} /$ day had no significant beneficial effect on left ventricular end-systolic volume compared with placebo (ASPIRE). ${ }^{92}$ Further studies are currently under way to evaluate the effect of aliskiren on the following clinical outcomes: reduction of cardiovascular death and heart failure rehospitalization events within 6 months in patients with congestive heart failure hospitalized for an episode of acute decompensated heart failure (Aliskiren Trial on Acute Heart Failure Outcomes [ASTRONAUT] $),{ }^{93}$ morbidity and mortality in patients with type 2 diabetes and pre-existing cardiovascular disease and/or kidney disease (Aliskiren Trial in Type 2 Diabetes Using Cardio-renal Disease Endpoints [ALTITUDE]), ${ }^{94}$ and morbidity and mortality in patients with chronic heart failure (Aliskiren Trial to Minimize Outcomes in Patients with Heart Failure [ATMOSPHERE]). ${ }^{95}$ The potential benefit of aliskiren on long-term outcomes is currently being evaluated as part of the larger ASPIRE HIGHER program $(n=35,000)$.

\section{Patient-focused perspectives}

Aliskiren can be employed in patients with hypertension, and in particular in subjects with proteinuria. Despite the possibility of an occasional forgotten dose (missing dose), it exerts protection beyond 24 hours due to its long half-life. This feature is not associated with a higher risk of hypotension. ${ }^{41}$ An important advantage is that aliskiren does not need to be adjusted in patients with hepatic or renal disease. As an antihypertensive drug, aliskiren is equivalent to any other drug and may not present major differences in blood pressure control when used as monotherapy, particularly at $300 \mathrm{mg} /$ day. However, in hypertensive patients with proteinuria, it may present some advantages. It can be used alone or in combination with other drugs to achieve low protein urinary excretion. Although aliskiren does not present a renal route of elimination and would potentially be useful at any stage of renal disease, there is still not enough information to recommend its use in chronic renal failure stages 4 or 5 . Patients with 
renin-dependent hypertension are a target population. In these cases, potassium levels must be monitored periodically. Diabetics appear to benefit from aliskiren, independently of being normotensive or hypertensive, normoalbuminuric, microalbuminuric, or proteinuric. Aliskiren can block prorenin activity, which is increased in diabetic subjects and associated with inflammatory processes systemically. Although plasma renin activity is suppressed by aliskiren, plasma renin concentration remains high, and the eventual consequences of this phenomenon are still unknown in the adult population. ${ }^{25}$

In patients with primary or secondary glomerulopathies, such as lupus nephritis, in which immunosuppression is the mainstay of treatment, once the acute process has been approached and renal function stabilized, aliskiren could be used alone or in combination with ARBs, ACEIs, or other antihypertensive drugs to inhibit angiotensin II-induced inflammatory processes (vascular remodeling, tissue fibrosis) to decrease proteinuria and the maintenance dose of immunosuppressants. In addition, in patients with glomerulopathies and moderate degrees of proteinuria (eg, immunoglobulin A, focal and segmental glomerulosclerosis), a first attempt to decrease protein excretion avoiding the use of immunosuppression could be the employment of aliskiren alone or in combination with other antihypertensive drugs, particularly ACEIs or ARBs.

\section{Conclusion}

Patients who could benefit most from aliskiren alone or in combination include glomerular proteinuric subjects and patients with moderate to high cardiovascular risk. As high plasma renin activity is regarded as a risk factor for myocardial infarction in untreated hypertensive and normotensive patients, this population could benefit from aliskiren prescription. ${ }^{48}$ Diuretics, $\beta$-blockers, and calcium channel blockers appear to be good options for combinations. Associations with ACEIs or ARBs should be preferentially reserved for proteinuric patients and, in this case, combinations should be approached in a step-by-step fashion, increasing doses gradually. Severe vasodilatation must be avoided, salt-free diets must be encouraged, and serum creatinine and potassium levels must be followed initially until the full designed dose is achieved. Proteinuria and blood pressure are the main goals to control.

\section{Disclosure}

Hernán Trimarchi is a consultant to Novartis.

\section{References}

1. Kearny PM, Whelton M, Reynolds K, et al. Global burden of hypertension: analysis of worldwide data. Lancet. 2005;365:217-223.
2. Ritz E. Hypertension. The kidney is the culprit even in the absence of kidney disease. Kidney Int. 2007;71:371-372.

3. Levington S, Clarke R, Qizilbash N. Age-specific relevance of usual blood pressure to vascular mortality: a meta-analysis of individual data for one million adults in 61 prospective studies. Lancet. 2002;360:1903-1913.

4. United States Renal Data System 2010 Annual Data Report, CD Vol 1, Chapter 1, Table ei, page 48.

5. United States Renal Data System 2010 Annual Data Report, CD Vol 1, Chapter 2, Table 19i, page 61.

6. United States Renal Data System 2010 Annual Data Report, CD Vol 2, Chapter 2, Table 2 10ii, page 258.

7. Bakris GL. Slowing nephropathy progression: focus on proteinuria reduction. Clin J Am Soc Nephrol. 2008;3 Suppl 1:S3-S10.

8. Peterson JC, Adler S, Burkart JM, et al. Blood pressure control, proteinuria, and the progression of renal disease. The Modification of Diet in Renal Disease Study. Ann Int Med. 1995;123:754-762.

9. De Zeew D, Remuzzi G, Parving HH, et al. Proteinuria, a target for renoprotection in patients with type 2 diabetic nephropathy:Lessons from RENAAL. Kidney Int. 2004;65:2309-2320.

10. Chobanian AV, Bakris GL, Black HR. Seventh Report of the Joint National Committee on Prevention, Detection, Evaluation, and Treatment of High Blood Pressure. Hypertension. 2003;42:1206-1252.

11. Bakris GL, Williams M, Dworkin L. Preserving renal function in adults with hypertension and diabetes: a consensus approach. National Kidney Foundation Hypertension and Diabetes Executive Committees Working Group. Am J Kidney Dis. 2000;36:646-661.

12. De Zeew D, Remuzzi G, Parving HH, et al. Albuminuria, a therapeutic target for cardiovascular protection in type 2 diabetic patients with nephropathy. Circulation. 2004;110:921-927.

13. KDOQI clinical practice guidelines and clinical practice recommendations for diabetes and chronic kidney disease. Am J Kidney Dis. 2007;49 Suppl 2:S1-S179.

14. Garg JP, Bakris GL. Microalbuminuria: marker of vascular dysfunction, risk factor for cardiovascular disease. Vasc Med. 2002;7:35-43.

15. Mancia G, De Backer G, Dominiczak A. 2007 guidelines for the management of arterial hypertension: the task force for the management of arterial hypertension of the European Society of Hypertension (ESH) and of the European Society of Cardiology (ESC). J Hypertens. 2007;25:1105-1187.

16. Linas SL. Are two better than one? Angiotensin converting enzyme inhibitors plus angiotensin receptor blockers for reducing blood pressure and proteinuria in kidney disease. Clin J Am Soc Nephrol. 2008;3 Suppl:S17-S23.

17. Azizi M, Menard J. Combined blockade of the renin-angiotensin system with angiotensin-converting enzyme inhibitors and angiotensin II type 1 receptor antagonists. Circulation. 2004;109:2492-2499.

18. Mooser V, Nussberger J, Jullierat L. Reactive hyperreninemia is a major determinant of plasma angiotensin II during ACE inhibition. J Cardiovasc Pharmacol. 1990;15:276-282.

19. Hollenberg NK, Fisher ND, Price DA. Pathways for angiotensin II generation in intact human tissue: evidence from comparative pharmacological interruption of the renin system. Hypertension. 1998;32:387-392.

20. Wolny A, Clozel JP, Rein J, et al. Functional and biochemical analysis of angiotensin II-forming pathways in the human heart. Circ Res. 1997;80: 219-227.

21. Fisher NDL, Allan D, Kifor I, et al. Responses of converting enzyme and renin inhibition: role of angiotensin II in humans. Hypertension. 1994;23:44-51.

22. Jeunemaitre X, Menard J, Nussberger J, et al. Plasma angiotensins, renin, and blood pressure during acute renin inhibition by CGP 38 560 A in hypertensive patients. Am J Hypertens. 1989;2:819-827.

23. Rahuel J, Rasetti V, Maibaum J, et al. Structure-based drug design: the discovery of novel non-peptide orally active inhibitors of human renin. Chem Biol. 2000;7:493-504.

24. Gradman AH, Schimieder RE, Lins RL, et al. Aliskiren, a novel orally effective renin inhibitor, provides dose-dependent antihypertensive efficacy and placebo-like tolerability in hypertensive patients. Circulation. 2005;111:1012-1018. 
25. Trimarchi H, Orias M. Aliskiren and the kidney: beyond hypertension. Nephrology Reviews. 2009;1:e1-e4.

26. Wood JM, Maibaum J, Rahuel J, et al. Structure-based design of aliskiren, a novel orally effective renin inhibitor. Biochem Biophys Res Commun. 2003;308:698-705.

27. Nguyen G, Delarue F, Burckle C, et al. Pivotal role of the renin/prorenin receptor in angiotensin II production and cellular responses to renin. J Clin Invest. 2002;109:1417-1427.

28. Feldt S, Batenburg WW, Mazak I, et al. Prorenin and renin-induced extracellular signal-regulated kinase $1 / 2$ activation in monocytes is not blocked by aliskiren or the handle-region peptide. Hypertension. 2008;51:682-688.

29. Deinum J, Ronn B, Mathiesen E, et al. Increase in serum prorenin precedes onset of microalbuminuria in patients with insulin-dependent diabetes mellitus. Diabetologia. 1999;42:1006-1010.

30. Chiarelli F, Pomilio M, De Luca FA, et al. Plasma prorenin levels may predict persistent microalbuminuria in children with diabetes. Pediatr Nephrol. 2001;16:116-120.

31. Nguyen G, Delarue F, Burckle C, et al. Pivotal role of the renin/prorenin receptor in angiotensin II production and cellular responses to renin. J Clin Invest. 2002;109:1417-1427.

32. Huang $\mathrm{Y}$, Wongamorntham $\mathrm{S}$, Kasting J, et al. Renin increases mesangial cell transforming growth factor beta and matrix proteins through receptor-mediated, angiotensin II-independent mechanisms. Kidney Int. 2006;69:105-113.

33. Benedict CR, Johnstone DE, Weiner DH. Relation of neurohumoral activation to clinical variables and degree of ventricular dysfunction: a report from the Registry of Studies of Left Ventricular Dysfunction J Am Coll Cardiol. 1994;23:1410-1420.

34. Kehoe B, Keeton GR, Hill C. Elevated plasma renin activity associated with renal dysfunction. Nephron. 1986;44:51-57.

35. Brunner HR, Laragh JH, Baer L. Essential hypertension: renin and aldosterone, heart attack and stroke. N Engl J Med. 1972;286:441-449.

36. Novartis. Tekturna (aliskiren) tablets $150 \mathrm{mg}$ and $300 \mathrm{mg}$ : US prescribing information. East Hanover (NJ): Novartis Pharmaceuticals Corporation. http://www.pharma.us.novartis.com/product/pi/pdf/ tekturna.pdf. Accessed March 4, 2011.

37. Vaidyanathan S, Jarugula V, Dieterich HA, et al. Clinical pharmacokinetics and pharmacodynamics of aliskiren. Clin Pharmacokinet. 2008;47:515-531.

38. Azizi M, Menard J, Bissery A, et al. Pharmacologic demonstration of the synergistic effects of a combination of the renin inhibitor aliskiren and the AT1 receptor antagonist valsartan on the angiotensin II-renin feedback interruption. J Am Soc Nephrol. 2004;15:3126-3345.

39. Vaidyanathan S, Camenisch G, Schuetz H, et al. Pharmacokinetics of the oral direct renin inhibitor aliskiren in combination with digoxin, atorvastatin, and ketoconazole in healthy subjects: the role of P-glycoprotein in the disposition of aliskiren. J Clin Pharmacol. 2008;48:1323-1338

40. Vaidyanathan S, Jarugula V, Dieterich HA, et al. Clinical pharmacokinetics and pharmacodynamics of aliskiren. Clin Pharmacokinet. 2008;47:515-531.

41. European Medicines Agency. Rasilez: summary of product characteristics. http://www.ema.europa.eu/docs/en_GB/document_library/ EPAR_-_Product_Information/human/000780/WC500047010.pdf. Accessed March 4, 2011.

42. Zhao C, Vaidyanathan S, Yeh CM, et al. Aliskiren exhibits similar pharmacokinetics in healthy volunteers and patients with type 2 diabetes mellitus. Clin Pharmacokinet. 2006;45:1125-1134.

43. Waldmeier F, Glaenzel U, Wirz B, et al. Absorption, distribution, metabolism, and elimination of the direct renin inhibitor aliskiren in healthy volunteers. Drug Metab Dispos. 2007;35:1418-1428.

44. Vaidyanathan S, Zhao C, Yeh C, et al. Pharmacokinetics and safety of the novel oral renin inhibitor aliskiren in patients with type 2 diabetes. Clin Pharmacol Ther. 2005;79 Suppl:S12.

45. Bartlett M, Vaidyanathan S, Karan RS, et al. Multiple dose pharmacokinetics of the direct renin inhibitor aliskiren in healthy Chinese subjects. Clin Pharmacol Ther. 2008;83 Suppl 1:S61-S62.
46. Vaidayanathan S, Jermany J, Yeh C, et al. Aliskiren, a novel orally effective renin inhibitor, exhibits similar pharmacokinetics and pharmacodynamics in Japanese and Caucasian subjects. Br J Clin Pharmacol. 2006;62:690-698.

47. Dieterich HA, Yeh C, Howard D, et al. Assessment of the pharmacokinetic interaction between the oral direct renin inhibitor aliskiren and furosemide: a study in healthy volunteers [abstract no. PIII-78]. Clin Pharmacol Ther. 2007;81 Suppl 1:S110.

48. Tapaninen T, Neuvonen PJ, NiemiM. Rifampicin reduces the plasma concentrations and the renin-inhibiting effect of aliskiren. Eur J Clin Pharmacol. 2010;66:497-502.

49. Nguyen G, Delarue F, Burckle C, et al. Pivotal role of the renin/prorenin receptor in angiotensin II production and cellular responses to renin. J Clin Invest. 2002;109:1417-1427.

50. Campbell DJ. Interpretation of plasma renin concentration in patients receiving aliskiren therapy. Hypertension. 2008;51:15-18.

51. Luft FC, Winberger MH. Antihypertensive therapy with aliskiren. Kidney Int. 2008;73:679-683.

52. Oparil S, Yarows SA, Patel S. Efficacy and safety of combined use of aliskiren and valsartan in patients with hypertension: a randomized, double-blind trial. Lancet. 2007;370:221-229.

53. Nguyen G. The (pro)renin receptor:pathophysiological roles in cardiovascular and renal pathology. Curr Opin Nephrol Hypertens. 2007;16:129-133.

54. Sealey JE, Laragh JH. Aliskiren, the first renin inhibitor for treating hypertension: reactive renin secretion may limit its affectiveness. $\mathrm{Am}$ J Hypertens. 2007;20:587-597.

55. Nussberger J, Aubert JF, Bouzourene K, et al. Renin inhibition by aliskiren prevents atherosclerosis progression. Comparison with irbesartan, atenolol, and amlodipine. Hypertension. 2008;51: 1306-1311.

56. Benedict CR, Johnstone DE, Weiner DH. Relation of neurohumoral activation to clinical variables and degree of ventricular dysfunction: a report from the Registry of Studies of Left Ventricular Dysfunction. J Am Coll Cardiol. 1994;23:1410-1420.

57. Kehoe B, Keeton GR, Hill C. Elevated plasma renin activity associated with renal dysfunction. Nephron. 1986;44:51-57.

58. Brunner HR, Laragh JH, Baer L. Essential hypertension: renin and aldosterone, heart attack and stroke. N Engl J Med. 1972;286:441-449.

59. Fisher ND, Hollenberg MK. Renin inhibition: what are the therapeutic opportunities? J Am Soc Nephrol. 2005;16:592-599.

60. Richter WF, Whitby BR, Chou RC. Distribution of remikiren, a potent orally active inhibotor of human renin, in laboratory animals. Xenobiotica. 1996;26:243-254.

61. Feldman DL, Persohn E, Schitz H, et al. Renal localization of the renin inhibitor aliskiren. J Clin Hypertens. 2006;8 Suppl A:A80.

62. Duggan ST, Chwieduk CM, Curran MP. Aliskiren. A review of its use as monotherapy and as combination therapy in the management of hypertension. Drugs. 2010;70:2011-1049.

63. Oh BH, Mitchell J, Herron JR, et al. Aliskiren, an oral rennin inhibitor, provides dose-dependent efficacy and sustained 24-hour blood pressure control in patients with hypertension. $J$ Am Coll Cardiol. 2007;49:1157-1163.

64. Oparil S, Yarows SA, Patel S, et al. Efficacy and safety of combined use of aliskiren and valsartan in patients with hypertension: a randomised double-blind trial [published erratum appears in Lancet. 2007;370(9598):1542]. Lancet. 2007;370:221-229.

65. Villamil A, Chrysant SG, Calhoun D, et al. Renin inhibition with aliskiren provides additive antihypertensive efficacy when used in combination with hydrochlorothiazide. J Hypertens. 2007;25: 217-226.

66. Kushiro T, Itakura $\mathrm{H}, \mathrm{Abo} \mathrm{Y}$, et al. Aliskiren, a novel oral renin inhibitor, provides dose-dependent efficacy and placebo-like tolerability in Japanese patients with hypertension. Hypertens Res. 2006;29:997-1005.

67. Gradman AH, Schmieder RE, Lins RL, et al. Aliskiren, a novel orally effective renin inhibitor, provides dose-dependent antihypertensive efficacy and placebo-like tolerability in hypertensive patients. Circulation. 2005;111:1012-1018. 
68. Weir MR, Prescott MF, Bush C, et al. Antihypertensive efficacy of the direct renin inhibitor aliskiren in patients with diabetes, metabolic syndrome or obesity: a pooled analysis of 10 randomized trials [abstract no. P888]. Circulation. 2008;118:162.

69. Andersen K, Weinberger MH, Egan B, et al. Comparative efficacy and safety of aliskiren, an oral direct renin inhibitor, and ramipril in hypertension: a 6-month, randomized, double-blind trial. J Hypertens. 2008;26:589-599.

70. Schmieder RE, Philipp T, Guerediaga J, et al. Long-term antihypertensive efficacy and safety of the oral direct renin inhibitor aliskiren: a 12-month randomized, double-blind comparator trial with hydrochlorothiazide. Circulation. 2009;119:417-425.

71. Krone W, Hanefeld M, Meyer H-F, et al. Comparative efficacy and safety of aliskiren and irbesartan in patients with hypertension and metabolic syndrome. J Hum Hypertens. 2011;25:186-195.

72. Pool JL, Schmieder RE, Azizi M, et al. Aliskiren, an orally effective renin inhibitor, provides antihypertensive efficacy alone and in combination with valsartan. Am J Hypertens. 2007;20:11-20.

73. Stanton A, Jensen C, Nussberger J, et al. Blood pressure lowering in essential hypertension with an oral renin inhibitor, aliskiren. Hypertension. 2003;42:1137-1143.

74. Dietz R, Dechend R, Yu CM, et al. Effects of the direct renin inhibitor aliskiren and atenolol alone or in combination in patients with hypertension. J Renin Angiotensin Aldosterone Syst. 2008;9:163-175.

75. Black HR, Kribben A, Aguirre Palacios F, et al. Aliskiren as monotherapy or in combination with hydrochlorothiazide provides effective BP lowering in patients with systolic BP $160 \leq 180 \mathrm{~mm} \mathrm{Hg}$ (ACQUIRE study) [abstract no. PO-15]. J Clin Hypertens. 2010; 12 Suppl 1:A24.

76. Chrysant SG, Murray AV, Hoppe UC, et al. Long-term safety, tolerability and efficacy of aliskiren in combination with valsartan in patients with hypertension: a 6-month interim analysis. Curr Med Res Opin. 2008;24:1039-1047.

77. Littlejohn TW 3rd, Trenkwalder P, Hollanders G, et al. Long-term safety, tolerability and efficacy of combination therapy with aliskiren and amlodipine in patients with hypertension. Curr Med Res Opin. 2009;25:951-959.

78. Geiger H, Barranco E, Gorostidi M, et al. Combination therapy with various combinations of aliskiren, valsartan, and hydrochlorothiazide in hypertensive patients not adequately responsive to hydrochlorothiazide alone. J Clin Hypertens. 2009;11:324-332.

79. Jordan J, Engeli S, Boye SW, et al. Direct renin inhibition with aliskiren in obese patients with arterial hypertension. Hypertension. 2007;49:1047-1055.

80. Basile J, Babazadeh S, LillestolM, et al. First-line aliskiren/hydrochlorothiazide combination treatment lowers BP more effectively than hydrochlorothiazide alone in older patients with stage 2 hypertension (ACTION study) [abstract no. PO-11]. J Clin Hypertens. 2010; 12 Suppl 1:A22.

81. Ferdinand K, Pool J, Weitzman R. Responses to aliskiren/HCTZ versus amlodipine on peripheral and central blood pressure in African American patients with stage 2 hypertension. $\mathrm{J}$ Am Coll Cardiol. 2010;55 (10 Supp1 1):A61.E586.
82. Zieve F, Yadao A, Yurkovic C, et al. Aliskiren with or without hydrochlorothiazide lowers blood pressure effectively in patients with stage 2 hypertension and metabolic syndrome [abstract no. PP.38.505]. J Hypertens. 2010;28 Suppl A:e600.

83. Townsend RR, Forker A, Rumpelt $\mathrm{P}$, et al. Initial combination therapy with aliskiren/hydrochlorothiazide is more effective than amlodipine in patients with stage 2 systolic hypertension and diabetes mellitus [abstract no. LB-PO-03]. J Clin Hypertens. 2010;12:534.

84. Uresin Y, Taylor AA, Kilo C, et al. Efficacy and safety of the direct renin inhibitor aliskiren and ramipril alone or in combination in patients with diabetes and hypertension. J Renin Angiotensin Aldosterone Syst. 2007;8:190-198.

85. Braun-Dullaeus RC, Zhang J, Hristoskova S, et al. First line therapy with aliskiren/amlodipine combination provides robust blood pressure reductions in patients with moderate to severe hypertension [abstract no. PO-22]. J Clin Hypertens. 2010;12 Suppl 1:A27.

86. Black H, Weinberger M, Purkayastha D, et al. Combination aliskiren/ amlodipine is more effective than amlodipine monotherapy in male and female African American subjects with stage 2 hypertension [abstract no. PO-20]. J Clin Hypertens. 2010;12 Suppl 1:A26.

87. Dietz R, Dechend R, Yu CM, et al. Effects of the direct renin inhibitor aliskiren and atenolol alone or in combination in patients with hypertension. J Renin Angiotensin Aldosterone Syst. 2008;9:163-175.

88. Parving HH, Persson F, Lewis JB, et al. Aliskiren combined with losartan in type 2 diabetes and nephropathy. $N$ Engl J Med. 2008;358:2433-2446.

89. Solomon SD, Appelbaum E, Manning WJ, et al. Effect of the direct renin inhibitor aliskiren, the angiotensin receptor blocker losartan, or both on left ventricular mass in patients with hypertension and left ventricular hypertrophy. Circulation. 2009;119:530-537.

90. McMurray JJV, Pitt B, Latini R, et al. Effects of the oral direct renin inhibitor aliskiren in patients with symptomatic heart failure. Circ Heart Fail. 2008;1:17-24.

91. Scirica BM, Morrow DA, Bode C, et al. Patients with acute coronary syndromes and elevated levels of natriuretic peptides: the results of the AVANT GARDE-TIMI 43 Trial. Eur Heart J. 2010;31:1993-2005.

92. Cleland JGF, Coletta AP, Buga L, et al. Clinical trials update from the American College of Cardiology meeting 2010: DOSE, ASPIRE, CONNECT, STICH, STOPAF, CABANA, RACE II, EVEREST II, ACCORD, and NAVIGATOR. Eur J Heart Fail. 2010;12:623-629.

93. Novartis. Six months efficacy and safety of aliskiren therapy on top of standard therapy, on morbidity and mortality in patients with acute decompensated heart failure (ASTRONAUT) [ClinicalTrials.gov identifier NCT00894387]. US National Institutes of Health. http://www. clinicaltrials.gov. Accessed March 4, 2011.

94. Novartis. Aliskiren trial in type 2 diabetes using cardiovascular and renal disease endpoints (ALTITUDE) [ClinicalTrials.gov identifier NCT00549757]. US National Institutes of Health. http://www.clini caltrials.gov. Accessed March 4, 2011.

95. Novartis. Efficacy and safety of aliskiren and aliskiren/enalapril combination on morbi-mortality in patients with chronic heart failure (ATMOSPHERE) [ClinicalTrials.gov identifier NCT00853658]. US National Institutes of Health. http://www.clinicaltrials.gov. Accessed March 4, 2011.

International Journal of Nephrology and Renovascular Disease

\section{Publish your work in this journal}

The International Journal of Nephrology and Renovascular Disease is an international, peer-reviewed open-access journal focusing on the pathophysiology of the kidney and vascular supply. Epidemiology, screening, diagnosis, and treatment interventions are covered as well as basic science, biochemical and immunological studies. The journal welcomes

\section{Dovepress}

original research, clinical studies, reviews \& evaluations, expert opinion and commentary, case reports and extended reports. The manuscript management system is completely online and includes a very quick and fair peerreview system, which is all easy to use. Visit http://www.dovepress.com/ testimonials.php to read real quotes from published authors. 